\title{
Modelling of periodic heterostructures based on tin and phosphorus chalcogenides
}

\author{
V.Yu.Klevets, N.D.Savchenko, T.N.Shchurova, \\ I.I.Opachko, K.O.Popovic
}

\author{
Uzhgorod National University, 13 Kapitulna, 88000 Uzhgorod, Ukraine \\ *NanoTecCenter Weiz Forschungsgesellschaft mbH, Franz-Pichler-Strasse \\ 32, A-8160 Weiz, Austria
}

Received August 24, 2012

\begin{abstract}
In terms of tight-binding approximation and pseudopotential theory the following energy parameters for binary tin and phosphorus chalcogenides: band gap, electron affinity energy and energy position of Fermi level have been calculated. The effect of spin-orbit interaction, chemical bond polarity, $d$-states, and the intra-atomic Coulomb repulsion energy on the energy band parameters has been analyzed. Energy band diagrams for binary tin and phosphorus chalcogenides, as well as for periodic SnSe-PSe heterostructures dependent on the way of Fermi level determination have been given.
\end{abstract}

В рамках приближения сильной связи и теории псевдопотенциала рассчитаны следующие энергетические параметры бинарных халькогенидов олова и фосфора: ширина запрещенной зоны, сродство к әлектрону и энергетическое положение уровня Ферми. Проанализировано влияние спин-орбитального взаимодействия, полярности химической связи, $d$-состояний, а также энергии внутриатомного кулоновского отталкивания на параметры энергетических зон. Приведены энергетические диаграммы бинарных халькогенидов олова и фосфора и энергетические диаграммы периодических гетероструктур SnSe-PSe с уровнем Ферми, определенным различным способом.

\section{Introduction}

Semiconductor periodic structures consisting of a large number of alternating heterojunctions are of a great interest both from a scientific point of view and in terms of their practical applications due to their new specific properties and physical effects.

Calculation of the electronic structure of solids from first principles allows prediction of a wide range of physical properties from their chemical composition. Up to date, physical properties of $S n-X$ and $P-X$ binary compounds (where $X=S$, Se, Te), i.e., band gap, electron affinity energy, Fermi level, etc., are not enough studied both theoretically and experimentally, so theoretical calculations of physical properties for these materials are of current interest. Moreover, theoretical calculations are important for correct interpretation of experimental data, search for their new effective practical applications in various fields of science and technology. The purpose of this work is to calculate the above mentioned parameters for of Sn-X and P-X compounds and to construct the energy diagrams for heterojunctions of different types. In this paper we have used theoretical approach developed in the works by W.A.Harrison [1,2] for the calculations. This approach was previously applied by us to the modelling the electronic structure of binary and ternary chalcogenide compounds [3-8].

\section{Calculation procedure}

Calculation of the energy parameters was performed by the method based on the linear combination of atomic orbitals method and pseudopotential theory [1]. We have 
Table 1. Atomic terms $\left(\varepsilon_{p}, \varepsilon_{s}, \varepsilon_{d}\right), p$ - and $d$-orbitals radii, intra-atomic Coulomb repulsion energy, spin-orbit splitting for $\mathrm{Sn}, \mathrm{P}, \mathrm{S}$, Se and Te atoms $[1,10]$

\begin{tabular}{||c|c|c|c|c|c||}
\hline & $\mathrm{Sn}$ & $\mathrm{P}$ & $\mathrm{S}$ & $\mathrm{Se}$ & $\mathrm{Te}$ \\
\hline$\varepsilon_{s}, \mathrm{eV}$ & -13.04 & -19.22 & -24.02 & -22.86 & -19.12 \\
$\varepsilon_{p}, \mathrm{eV}$ & -6.76 & -9.54 & -11.60 & -10.68 & $-9.54-$ \\
$\varepsilon_{d}, \mathrm{eV}$ & -37.36 & - & - & - & - \\
$r_{p}, \mathrm{~nm}$ & 1.80 & 1.14 & 1.01 & 1.21 & 1.59 \\
$r_{d}, \mathrm{~nm}$ & 0.0469 & - & - & - & - \\
$U, \mathrm{eV}$ & 6.73 & 8.57 & 9.45 & 9.07 & 8.00 \\
$\Delta E_{s-o}, \mathrm{eV}$ & 0.267 & 0.022 & 0.025 & 0.160 & 0.367 \\
\hline
\end{tabular}

also used the methods of construction of the energy band diagrams of heterojunctions [7-9]. The energy structure of the compounds under investigation was calculated using Hartree-Fock atomic terms, and taking into account the corrections for the effect of chemical bond polarity on the energy of the metallic bond, the spin-orbit interaction, the influence of $d$-states on the valence band offset and the intra-atomic Coulomb repulsion energy. Atomic terms $\left(\varepsilon_{p}, \varepsilon_{s}\right.$, $\varepsilon_{d}$ ) for $s$-, $p$-, and $d$-orbitals obtained in Hartree-Fock approximation, intra-atomic Coulomb repulsion energy $(U)$, and spinorbit splitting $\left(\Delta E_{s-o}\right)$ used for the construction of the energy band diagrams are listed in Table 1. Calculations were carried out in $\Gamma$ point that is the centre of Brillouin zone.

The band gap $E_{g}$ for binary chalcogenides were determined from calculated values of the valence band maximum $E_{v}$ and the conduction band minimum $E_{c}: E_{g}=E_{c}-E_{v}$ accounting for bond polarity, $\alpha_{p}$, spin-orbit splitting of the valence band, $\Delta E_{s-o}$, and the effect of $p d$ coupling on the shift of the valence band maximum $\Delta E_{v p d}=E_{p d}{ }^{2} /\left(\varepsilon_{p}-\varepsilon_{d}\right)$ $[1,10]$. Energy position of the conduction band minimum was defined from the expression:

$$
E_{c}=\frac{\varepsilon_{p}^{+}+\varepsilon_{p}^{-}}{2}+\sqrt{\left(V_{2}\right)^{2}+\left(V_{3}\right)^{2}}-V_{1}^{\sigma^{*}} .
$$

The valence band maximum for $S n-X$ compounds were obtained from the equation:

$$
\begin{aligned}
E_{v}= & \frac{\varepsilon_{p}^{+}+\varepsilon_{p}^{-}}{2}-\sqrt{\left(V_{2}\right)^{2}+\left(V_{3}\right)^{2}}+ \\
& +\Delta E_{v_{p d}}-\Delta E_{s-o}+V_{1}^{\sigma} .
\end{aligned}
$$

For P-X compounds the energy positions of the valence band maximum were taken to be $\mathrm{X} p$ atomic terms. LP-bands are formed by splitting of the respective atomic term: $\Delta E_{L P}= \pm 0.63 \hbar^{2} / m d^{2}[1]$.

Values $V_{1}, V_{2}$ and $V_{3}$ in Eqs. (1) and (2) stand for the energy of metallic, covalent and polar bonds. The energy of the metallic bond is determined from the expression: $V_{1}=\left(V_{1}^{+}+V_{1}^{-}\right) / 2$, where $V_{1}^{+(-)}=\left(\varepsilon_{p}-\varepsilon_{s}\right) / 4$. The covalent bond energy for $S n-X$ compounds is determined from the expression:

$$
\begin{aligned}
V_{2}=-\frac{1}{4}\left(V_{s s \sigma}\right. & \left.+2 \sqrt{3} V_{s p \sigma}-3 V_{p p \sigma}\right) \frac{\hbar^{2}}{m d^{2}}= \\
& =3.22 \frac{\hbar^{2}}{m d^{2}}
\end{aligned}
$$

where $V_{s s \sigma}=-1.32 \hbar^{2} / m d^{2}-$ bonding $s s$ state energy, $V_{p p \sigma}=2.22 \hbar^{2} / m d^{2}$ - bonding $p p$ state energy, $V_{s p \sigma}=1.42 \hbar^{2} / m d^{2}-$ bonding $s p$ state energy, d - interatomic distance, $\hbar$ - Planck's constant. The covalent bond energy for P-X compounds was calculated as $V_{2}=2.89 \hbar^{2} / m d^{2}$. The polar bond energy: $V_{3}=-\left(\varepsilon_{\mathrm{p}}{ }^{+}-\varepsilon_{\mathrm{p}}{ }^{-}\right) / 2$. The metallic bond energy accounting for the bond polarity for antibonding and bonding states was found from the equations, respectively:

$$
\begin{aligned}
& V_{1}^{\sigma^{*}}=1 / 2\left[\left(1-\alpha_{p}\right) V_{1}^{+}+\left(1+\alpha_{p}\right) V_{1}^{-}\right], \\
& V_{1}^{\sigma}=1 / 2\left[\left(1+\alpha_{p}\right) V_{1}^{+}+\left(1-\alpha_{p}\right) V_{1}^{-}\right],
\end{aligned}
$$

where $\alpha_{p}$ - bond polarity is defined as $\alpha_{\mathrm{p}}=$ $V_{3} /\left(V_{2}^{2}+V_{3}^{2}\right)^{1 / 2}$.

Electron affinity, $\chi$, was determined following the formula: $\chi=E_{v a c}-E_{c}-U / 2$, where $U=\left(U^{+}+U^{-}\right) / 2$.

The $p d$ coupling energy for $S n-X$ compounds was defined as 
Table 2. Interatomic distances and energy parameters for $\mathrm{S} n-\mathrm{X}$ and $\mathrm{P}-\mathrm{X}$ compounds

\begin{tabular}{|c|c|c|c|c|c|c||}
\hline \hline Parameter & SnS & SnSe & SnTe & PS & PSe & PTe \\
\hline$d, \mathrm{~nm}$ & 0.329 & 0.334 & 0.316 & 0.200 & 0.222 & 0.223 \\
$d^{S n-S n}, \mathrm{~nm}$ & 0.349 & 0.355 & 0.446 & - & - & - \\
$d^{\mathrm{P}-\mathrm{P}}, \mathrm{nm}$ & - & - & - & 0.200 & 0.200 & 0.200 \\
$V_{1}{ }^{*}, \mathrm{eV}$ & 2.90 & 2.80 & 2.18 & 2.83 & 2.77 & 2.41 \\
$V_{1}{ }^{\sigma}, \mathrm{eV}$ & 1.78 & 1.77 & 1.78 & 2.70 & 2.69 & 2.41 \\
$V_{2}, \mathrm{eV}$ & 2.27 & 2.20 & 2.46 & 5.51 & 4.47 & 3.82 \\
$V_{3}, \mathrm{eV}$ & 2.42 & 1.96 & 1.39 & 1.03 & 0.57 & 0 \\
$U / 2, \mathrm{eV}$ & 4.05 & 3.95 & 3.68 & 4.51 & 4.41 & 4.14 \\
$-E_{c}, \mathrm{eV}$ & 4.71 & 4.62 & 3.83 & 3.29 & 3.88 & 3.99 \\
$-E_{v}, \mathrm{eV}$ & 6.67 & 5.95 & 5.51 & 7.09 & 6.27 & 6.17 \\
$-E_{F 1}, \mathrm{eV}$ & 5.69 & 5.29 & 4.67 & 5.19 & 5.08 & 4.70 \\
$-E_{F 2}, \mathrm{eV}$ & 5.49 & 5.36 & 5.35 & 5.03 & 5.13 & 5.40 \\
$-E_{g}, \mathrm{eV}$ & 1.96 & 1.33 & 1.68 & 3.80 & 2.39 & 1.41 \\
$-E_{s}, \mathrm{eV}$ & 5.42 & 5.41 & 5.51 & 5.31 & 5.31 & 5.31 \\
$\Delta \Phi_{1}, \mathrm{eV}$ & -0.27 & 0.12 & 0.84 & -0.12 & 0.23 & 0.61 \\
$\Delta \Phi_{2}, \mathrm{eV}$ & -0.07 & 0.05 & 0.16 & 0.28 & 0.18 & -0.09 \\
$\Delta E_{L P}, \mathrm{eV}$ & 0.44 & 0.43 & 0.48 & 1.20 & 0.97 & 0.83 \\
$-\Delta E_{s-o}, \mathrm{eV}$ & 0.145 & 0.214 & 0.317 & 0.024 & 0.091 & 0.195 \\
\hline
\end{tabular}

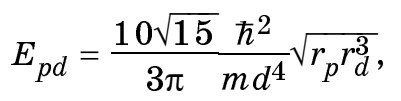

where $r_{p}$ and $r_{d}-$ radii of $p$ - and $d$-orbitals, respectively [10].

Energy positions of surface electronic states were calculated from the expression:

$$
E_{s}=\varepsilon_{p}^{+}+2.22 \frac{\hbar^{2}}{m\left(d^{\operatorname{Sn}(\mathrm{P})-\mathrm{Sn}(\mathrm{P})}\right)^{2}} .
$$

Energy positions of Fermi level were determined by two ways: 1) was fixed in the middle of the band gap:

$$
E_{F_{1}}=\frac{1}{2}\left(E_{v}+E_{c}\right)
$$

and 2) calculated from the expressions:

a) for $S n-X$

$$
E_{F_{2}}=\frac{\varepsilon_{p}^{S n}+\varepsilon_{p}^{X}}{4}+\frac{\varepsilon_{p}^{S n}+\varepsilon_{s}^{S n}}{4}+\frac{U}{2}
$$

b) for $\mathrm{P}-\mathrm{X}$

$$
E_{F_{2}}=\varepsilon_{p}^{p}+\frac{U}{2}
$$

Surface bending of the energy bands was derived as:

$$
\Delta \Phi=E_{F}-E_{s} .
$$

Energy band diagrams were constructed in the same way to the ones for heterostructures [9]. It was assumed, that surface bending of the energy bands at the heterojunction interfaces is described by power dependence.

Interatomic distances were selected on the basis of the analysis of theoretical and experimental data obtained by different methods for probable structural complexes in the investigated systems similarly to the procedure described in [5-7].

\section{Results and discussion}

Interatomic distances $\left(d, d^{\mathrm{Sn}-\mathrm{Sn}}, d^{\mathrm{P}-\mathrm{P}}\right)$ and the following calculated energy parameters are presented in Table 2: metallic bond energy accounting the bond polarity for antibonding and bonding states $\left(V_{1}{ }^{\sigma}, V_{1}{ }^{\sigma *}\right)$, covalent $\left(V_{2}\right)$ and polar bond energy $\left(V_{3}\right)$, intra-atomic Coulomb repulsion energy $(U)$, energy positions of the conduction-band minimum $\left(E_{c}\right)$, valence-band maximum $\left(E_{v}\right)$, Fermi levels determined from Eq.(8), (9) and (10) $\left(E_{F 1}\right.$ and $\left.E_{F 2}\right)$, band gap $\left(E_{g}\right)$, energy positions of surface electronic states $\left(E_{s}\right)$, surface bending of the energy bands $\left(\Delta \Phi_{1}\right.$ and $\left.\Delta \Phi_{2}\right)$, LP-band width $\left(\Delta E_{\mathrm{LP}}\right)$, spin- 

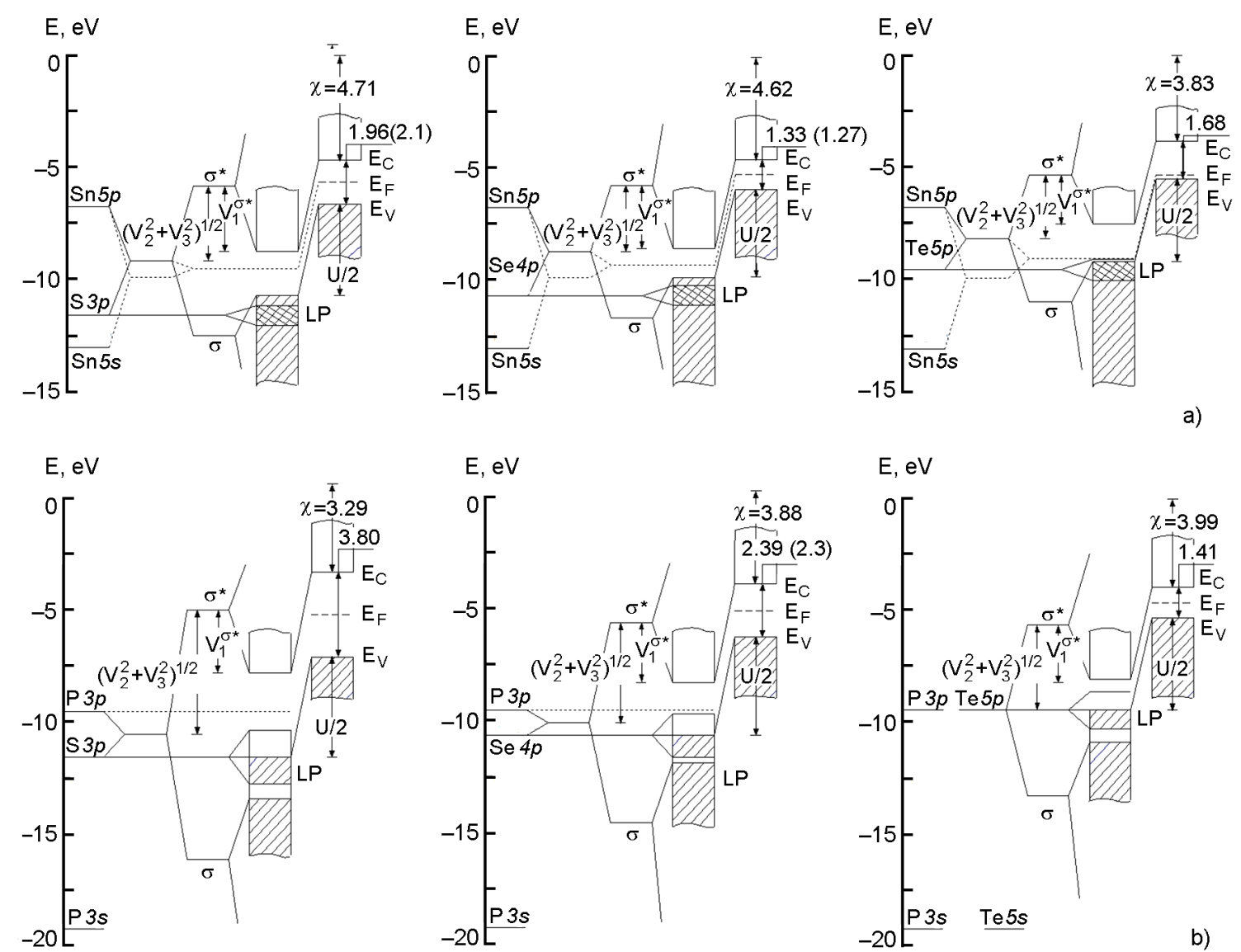

a)

Fig. 1. Sequence of the energy bands formation for $S n-X(a)$ and $P-X(b)$ compounds.

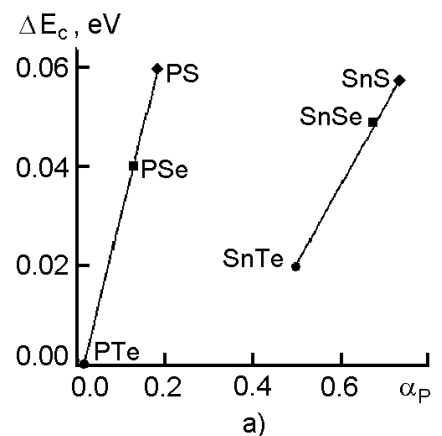

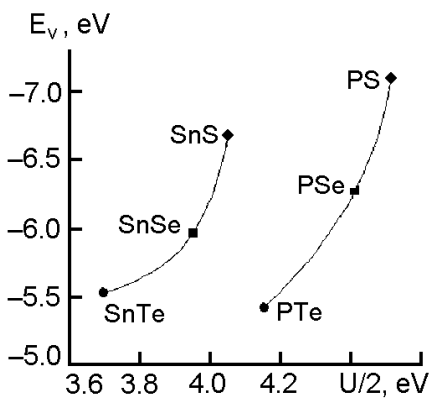

b)

$$
E_{v}, e V
$$

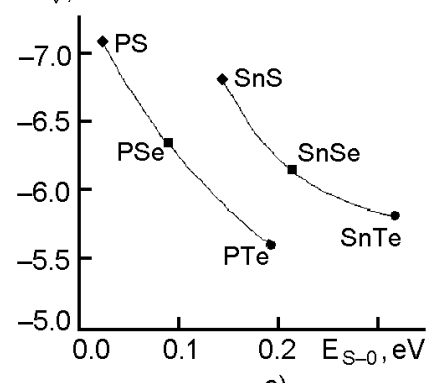

c)

Fig. 2. Correlation between calculated energy band parameters and input data for Sn-X and P-X compounds: a) shift of the conduction band minimum versus bond polarity; b) valence band maximum versus intra-atomic Coulomb repulsion energy; c) valence band maximum versus spinorbit splitting. Lines are given as a guide to the eye.

orbit splitting of the valence band $\left(\Delta E_{s-o}\right)$ for SnX and PX compounds.

The sequence of energy bands formation from atomic terms via bonding $\sigma$ and antibonding $\sigma^{*}$ atomic states for $\mathrm{S} n-\mathrm{X}$ and $\mathrm{P}-\mathrm{X}$ compounds is shown in Figs. $1 \mathrm{a}$ and b. Experimental band gap values taken from [11] (Fig. 1a) and [12] (Fig. 1b) are given in parentheses. Dashed lines show the second way to determine energy position of Fermi level for Sn-X and for P-X compounds following Eqs.(9) and (10), respectively. As it is seen from Fig. 1a, the valence band maximum is formed by bonding $\sigma(\mathrm{S} n p / \mathrm{X} p)$ states. Conduction band minimum is formed by splitting of antibonding $\sigma^{*}(\mathrm{~S} n p / \mathrm{X} p)$ states. For $\mathrm{P}-\mathrm{X}$ compounds energy position of the valence band maximum is determined by LP-states of chalcogen atoms, and con- 

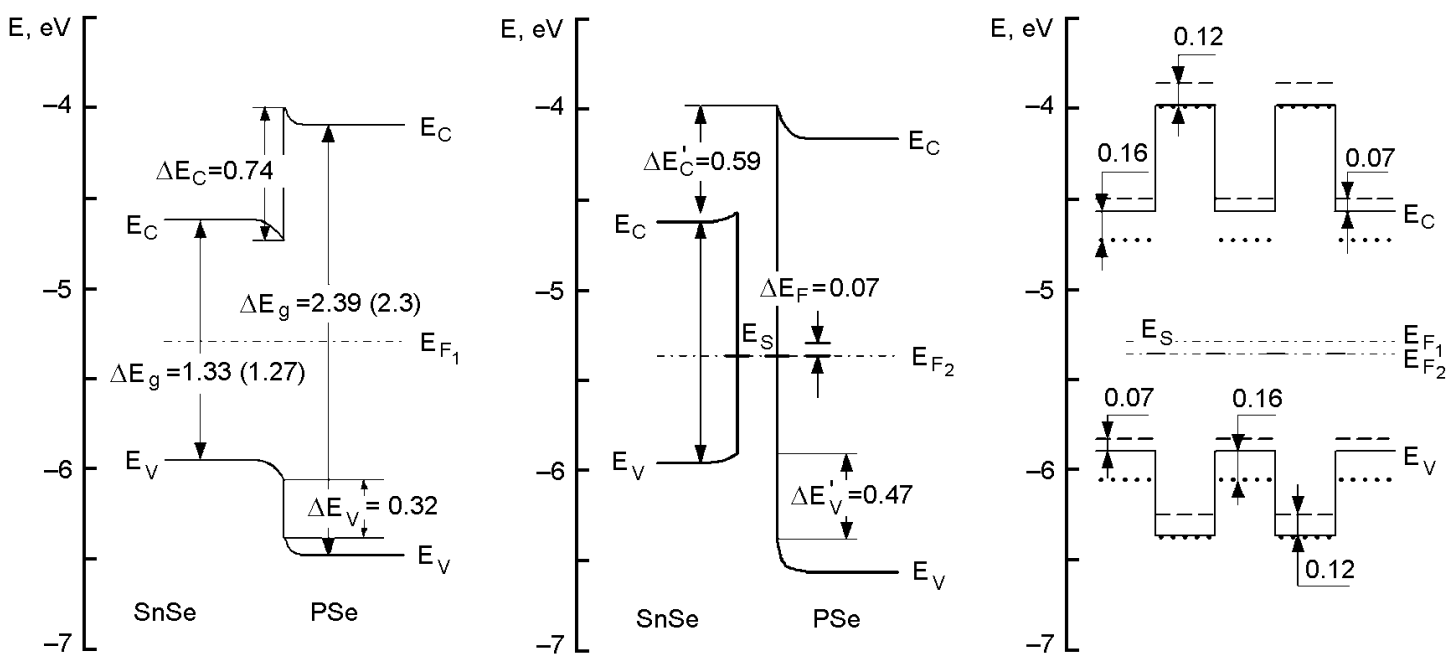

Fig. 3. Energy band diagrams of SnSe-PSe heterojunction with Fermi level calculated from Eq.(8) (a), from Eqs. (9) and (10) with account of surface states (b) and periodic nanoheterostructure (c).

duction band minimum is determined by antibonding $\sigma^{*}(\mathrm{P} p / \mathrm{X} p)$ states.

Fig. 2 illustrates interrelation between calculated energy parameters and input data for $\mathrm{S} n-\mathrm{X}$ and $\mathrm{P}-\mathrm{X}$ compounds. As it is seen from Fig. 2a, the shift of the conduction band minimum increases with bond polarity, and differs by the order of magnitude under transition from $\mathrm{P}-\mathrm{X}$ to $\mathrm{S} n-\mathrm{X}$ compounds. Correlation between valence band maximum with intra-atomic Coulomb repulsion energy and with spin-orbit splitting is shown in Fig. 2b and Fig. 2c, respectively.

Fig. 3 shows an example of analysis procedure and construction of the energy band diagram for probable periodic nanoheterostructures based on SnSe and PSe compounds. The effect of surface states resulting in the surface bending of the energy bands along with the changes of the energy position of Fermi level, $\left(\Delta E_{F}\right)$, depending on the way of calculation (see Eqs.(8)-(10)) are displayed in Fig. 3a, b. Energy band diagrams shown in Fig. 3c give an idea about the contribution of different components taken into account in the modelling procedure. Solid lines in this figure shows energy band diagram accounting for all the components. Positions of the energy levels for the heterostructure without account of the above-mentioned components are given by dots. The effect of the way of Fermi level calculation on the energy band diagram is shown by dashed lines. The numerical values in Fig. 3 are given in electron-volts.

\section{Conclusions}

Electron affinity energy, band gap and Fermi level for tin and phosphorus chalcogenides have been calculated by the method based on the method of linear combination of atomic orbitals and pseudopotential theory. The applicability of the proposed approach to the simulation of the energy band diagrams of different type heterostructures is shown.

\section{References}

1. W.A.Harrison, Elementary Electronic Structure. World Scientific Publishing Co., New Jersey, London, Singapore (2004).

2. W.A.Harrison, Theoretical Alchemy. Modelling Matter. World Scientific Publishing Co., New Jersey, London, Singapore (2010).

3. N.D.Savchenko, A.B.Kondrat, T.N.Shchurova et al., in: Proc. Ukr. Vac. Soc. 8th Int. Symp. Thin Films in Electronics, Kharkiv, Ukraine (1997), p.262.

4. T.Shchurova, N.Savchenko, A.Spesivykh et al., Jap.J.Appl. Phys., 39, 334 (2000).

5. N.D.Savchenko, T.N.Shchurova, K.O.Popovych et al., Semicond. Phys., Quant. Electron. \& Optoelectron., 7, 133 (2004).

6. T.Shchurova, N.Savchenko, V.M.Rubish et al., J.Optoelectron. and Adv.Mater., 7, 2021 (2005).

7. N.D.Savchenko, T.N.Shchurova, A.B.Kondrat et al., Surf. Interface Anal., 38, 448 (2006).

8. T.Shchurova, N.Savchenko, A.Kondrat et al., Photoelectronics, 17, 104 (2008).

9. A.G.Milnes, D.L.Feucht, Heterojunctions and Metal Semiconductor Junctions, Academic Press Inc., New York (1972).

10. S.B.Zhang, S.H.Wei, A.Zunger, Phys.Rev.B, 52, 13975 (1995). 
11. I.Lefebvre, M.A.Szymanski, J.Olivier-Fourcade et al., Phys. Rev.B, 58, 1896 (1998).
12. Z.U.Borisova, Semiconductor Chalcogenide Glasses, Leningrad University Publ., Leningrad (1983) [in Russian].

\title{
Моделювання періодичних гетероструктур на основі халькогенідів олова та фосфору
}

\author{
В.Ю.Клевещь, М.Д.Савченко, Т.М.Щурова, \\ I.I.Oпачко, К.O.Попович
}

У рамках наближення сильного зв'язку та теорії псевдопотенціалу розраховано такі енергетичні параметри бінарних халькогенідів олова та фосфору: ширина забороненоі зони, спорідненість до електрона та енергетичне положення рівня Фермі. Проаналізовано вплив спін-орбітальної взаємодії, полярності хімічного зв'язку, $d$-станів, а також, енергії внутрішньоатомного кулонівського відштовхування на параметри енергетичних зон. Наведено енергетичні діаграми бінарних халькогенідів олова та фосфору і періодичних гетероструктур SnSe-PSe при різних способах визначення рівня Фермі. 